\title{
Produção de Sentidos no Começo da Vida
}

\author{
Nadja Maria Vieira da Silva \\ Universidade Federal de Alagoas
}

\begin{abstract}
RESUMO
Neste estudo discutiu-se a atividade de produção de sentidos no início da vida apontando-se a operação de processos co-regulados. Trata-se de um estudo longitudinal da interação de uma díade mãe-bebê. A partir de uma análise microgenética foi demonstrada uma trajetória de desenvolvimento da comunicação mediada por brinquedos. Nessa trajetória destacaram-se perfis de negociação no compartilhamento de atenção revelados em reorganizações frequentes. A produção de sentidos foi concebida como atos de responsividade relacionados com experiências passadas e com antecipações de possibilidades de experiências futuras envolvendo o brinquedo. Concluiu-se que a produção de sentidos na interação são situações de resolução momentânea de tensões promovidas por essa dinâmica de ações para onde convergem, simultaneamente, as experiências passadas e expectativas de possibilidades futuras.
\end{abstract}

Palavras-chave: Comunicação mãe-bebê; historicidade; análise microgenética.

\begin{abstract}
Making sense in early life

In this study we discuss about the activity of making senses in early life pointing to settings in the operation from co-regulated processes. This is a case study, with longitudinal data of interaction from one dyad mother-babe. From a micro-genetic analysis it was demonstrated a developmental trajectory of communicative actions mediated by toys. In this trajectory we highlight profiles from sharing attention that was in frequent reorganizations. The making sense activity was designed as responsivity acts which were linked to the past experiences and anticipation of possibilities of future experience involving the toy. It was concluded that the making sense are situations of momentary resolution of tensions promoted by this dynamic of actions, that reflect simultaneously past and future.
\end{abstract}

Keywords: Mother-baby communication; historicity; microgenetic analysis.

\section{Produção de sentidos no começo da vida}

A produção de sentidos inclui processos de interesse de filósofos da linguagem, linguistas e pesquisadores das ciências sociais e humanas. Aqui se apresenta uma abordagem psicológica desses processos. Defende-se que o estudo desses processos deve abranger uma dimensão pragmática da função comunicativa, inclusive suas configurações circunstanciais com intensa variabilidade, típicos dos usos da linguagem (Wittgenstein, 1958/1999; Bakhtin, 1979/2011; 1981/2010). Considera-se que a produção de sentidos reflete uma dinâmica complexa entre processos comunicativos que se manifestam em constante mudança e atualização, e são geridos por uma criatividade ontologicamente ativada, relacionados com a história e cultura dos falantes agindo no mundo.

Alinhados com esta opinião estão argumentos de pesquisadores que concebem os processos comunicativos como constitutivos do desenvolvimento humano.
Silva e Vasconcelos (2013), por exemplo, apresentaram uma análise de processos microgenéticos da atividade comunicativa e revelaram a função da alteridade na relação entre fala e ação enquanto característica do desenvolvimento do self através do desenho infantil. Bertau, Gonçalves e Raggatt (2013), refletindo também a perspectiva do self dialógico, afirmaram que o desenvolvimento infantil está condicionado à alteridade, de modo que seu curso é determinado pelas formas de interação e trocas, com os outros e com o mundo. Focalizando o desenvolvimento da comunicação no começo da vida, Scorsi e Lyra (2013) apontaram como os enunciados, o ritmo e a entonação utilizados pelo adulto na relação com o bebê surgem como resultado das trocas e rotinas co-construídas em cada momento pela díade.

O presente estudo explorou uma forma de conceber a produção de sentidos eminentemente relacionada com o desenvolvimento humano. Assumindo-se o começo da vida como lócus privilegiado para essa investigação, 
reforçou-se a orientação para análise genética das funções mentais superiores apresentada por Vigotski (1934/2010; 1984/2010). Segundo essa orientação, o método adequado para investigação dos processos de desenvolvimento humano é aquele que analisa a história do fenômeno focalizado.

\section{Linguagem, Diálogo e Produção de Sentidos}

A linguagem como diálogo foi proposição defendida por Bakhtin e Volochinov (1977/2009) e Bakhtin (1981/2010), como oposição ao estruturalismo mais tradicional na linguística sustentado, principalmente, por Saussure. Essa oposição inspirou, posteriormente, muitos pesquisadores da linguagem humana alinhados com um amplo processo de ruptura com pressupostos das mais diversas teorias que tinham por base uma visão representacional, lógico-formal e monológica da linguagem. O movimento conhecido como "virada linguística" orientou mudanças na filosofia, nas ciências humanas e sociais, para preterir essa visão logicaformal da linguagem e adotar uma atenção especial a sua função nas práticas humanas (Wittgenstein, 1958/1999; Drummond, 2013; Oliveira, 2006).

Os esforços teóricos de Bakhtin para evidenciar a dimensão criativa da linguagem, ou melhor, compor uma definição de linguagem como diálogo foram referências marcantes para a presente proposição de uma análise do diálogo entre mãe e bebê. Entre esses esforços mais conhecidos foi a caracterização do diálogo na obra de Dostoievski: "O esquema básico do diálogo em Dostoievski é muito simples: a contraposição do homem ao homem como contraposição do 'eu' ao 'outro" (Bakhtin, 1981/2010, p. 293). Assumindo-se ser o diálogo a questão central para uma abordagem psicológica da produção de sentidos é oportuno também resgatar a interpretação de Holquist (1994) quando se referiu à expressão de "existência como diálogo" (Holquist, 1994, p. 14), capturada na obra de Bakhtin. Nessa interpretação, Holquist declarou:

No centro de tudo o que Bakhtin já fez, pelo que sabemos dos muitos manuscritos (perdidos) até o trabalho mais recente (ainda não publicado), está um conceito altamente distintivo de linguagem. A concepção tem como, permitido a priori, um sentido quase maniqueísta de oposição e luta no coração da existência; uma batalha incessante entre as forças centrífugas a tentar manter as coisas separadas, e as forças centrípetas que se esforçam para tornar as coisas coerentes (Bakhtin, 1981/2010, pp. XVIII-XIX).

No aprofundamento das discussões acerca da linguagem e situando-a como questão fundamental para todas as atividades humanas, Bakhtin e Voloschinov
(1977/2009) destacaram que existe uma relação de reciprocidade entre dimensões internas e externas da experiência humana e, por essa razão, o funcionamento psicológico humano tem uma origem social. Com esses apontamentos, esses autores descaracterizaram o "subjetivismo abstrato" onde se considerava a primazia do interior do organismo e colocaram a linguagem no cerne do "que se chama individualidade criadora" que " constitui a expressão do núcleo central sólido e durável da orientação social do indivíduo" (Bakhtin \& Volochinov, 1977/2009, p. 121).

A orientação para uma concepção de linguagem essencialmente relacionada com a vida e as práticas humanas também caracterizou o trabalho de Vigotski $(1984 / 2010 ; 1934 / 2010)$ e de pesquisadores recentes que referenciam o seu trabalho (Vieira \& Henriques, 2014; Motta, Rafalski, Rangel \& Souza, 2013; Valsiner 2012, etc.). Para Vigotski (1934/2010) a linguagem é viva e dinâmica, com propriedades para constituir e não apenas para representar algo já realizado. Nas suas explicações sobre o funcionamento mental é relevante o modo como se cria realidades com características que reúnem um percurso de experiências de quem está agindo, com a história de seus costumes e valores, numa relação de reciprocidade entre o que existe e o que emerge na ação. Esse ato criativo e situado foi caracterizado no cruzamento da fala com a ação.

O uso do termo diálogo é menos visível nos textos de Vigotski que nos textos de Bakhtin. Entretanto é possível reconhecê-lo como subjacente, principalmente, às transformações das relações interpsicológicas em intrapsicológicas. Considerando também características dessas transformações denota-se que está subjacente às observações realizadas, tanto por Bakhtin quanto Vigotski, o reconhecimento de uma experiência de tensão e conflito que inviabiliza qualquer homogeneidade ou estabilidade nas práticas humanas com a linguagem, uma vez que esta torna ativa a relação entre processos de diferentes naturezas como caráter fundamental do funcionamento psicológico.

\section{A Experiência Dupla: Passado e Futuro no Presente}

Defende-se aqui que na fusão dos processos referidos pelos conceitos de linguagem, diálogo e produção de sentidos pressupõe-se, também, uma negociação das experiências no tempo (passado, futuro e agora) e em espaços diferentes (aqui e lá). Assumindo-se essa visão de linguagem como diálogo no presente estudo, a produção de sentidos foi tomada não como conteúdos lexicais, mas como atos responsivos nos quais, os seres 
humanos transformam na janela do presente, experiências já vividas (passadas) em antecipações de suas possibilidades no futuro. Acredita-se que essa dinâmica temporal do diálogo impulsiona um estado de tensão nas práticas humanas com a linguagem. Este processo foi objeto de análises que serão posteriormente apresentadas. Nessas análises destacou-se como o resgate de experiências anteriores e antecipações de possibilidades futuras da interação constituíram a produção de sentidos.

Resume-se então que, na base da produção de sentidos, de acordo com Bakhtin (1979/2010), se sustenta uma experiência dupla; por sentido se traduz um direcionamento das experiências humanas, ao relacionar ocorrências do antes (passado) com o depois (futuro). Esse direcionamento tem características temporárias, circunstanciais, pois se configura na negociação em ação, no agora (presente).

A partir desses pressupostos, realizou-se um estudo com o objetivo de investigar a produção de sentidos na comunicação no começo da vida. Neste estudo, exploraram-se alternativas para se destacar a relevância da produção de sentidos no funcionamento psicológico humano, uma vez que esse tema tem sido predominantemente estudado no campo da linguística clássica, a partir do enfoque no conteúdo das palavras. Como aspecto relevante para o funcionamento psicológico destacou-se o papel da experiência espaço-temporal na produção de sentidos, em oposição à ênfase em estruturas fonológicas e semânticas. Em outras palavras, centralizou-se aqui o interesse por explicar a produção de sentidos como atos configurados em situações imediatas, onde se reorganizam a experiência psicológica da linguagem na sua função de efetuar vínculos entre o passado (conhecido, vivido) e a expectativa do futuro (desconhecido antecipado).

\section{METODOLOGIA}

Apresenta-se a seguir uma análise microgenética de um caso com dados longitudinais. A análise microgenética é uma abordagem qualitativa de dados. Lavelli, Pantoja, Hsu, Messinger e Fogel (2002), caracterizaram a análise microgenética como uma observação densa que permite ao pesquisador traçar a trajetória individual do desenvolvimento de um determinado comportamento ao longo da faixa de idade investigada, assim como a identificação de pontos de transição de um padrão de comportamento prevalecente para outro, que poderia não ser capturado nas abordagens longitudinais típicas tradicionais. Além disso, a análise microgenética é uma abordagem fenomenológica, na medida em que é responsabilidade do pesquisador fazer inferências para explicar as transformações microgenéticas capturadas nos dados (Sinha, 2013).

O projeto para esta pesquisa foi aprovado por um Comitê de Ética em Pesquisa. Os dados analisados na presente investigação foram registros em vídeos da interação de uma díade mãe-bebê em um período de 40 semanas de vida do bebê. No início dos registros, o bebê estava com a idade de quatro semanas. O convite para que a mãe participasse deste estudo foi realizado pela pesquisadora e a confirmação de uma decisão voluntária se oficializou no ato em que a mãe assinou o TCLE - Termo de Consentimento Livre e Esclarecido. Através deste, ela permitiu também o uso das imagens (suas e de seu filho) que ilustraram o presente artigo.

Os registros em vídeos foram realizados uma vez por semana pela pesquisadora responsável por esta pesquisa, em um laboratório de comunicação no começo da vida. As sessões para esses registros tiveram duração média de vinte minutos e foram conduzidas sempre em um mesmo cenário, elaborado também pela pesquisadora, onde se encontravam, invariavelmente, uma cadeira e alguns brinquedos (sempre os mesmos brinquedos - um telefone, um boneco do Mickey e dois chocalhos). Como instrução para o início dos registros foi dito para a mãe que ela se comportasse naturalmente, satisfazendo as necessidades do bebê que surgissem durante o intervalo das gravações. Nenhuma instrução específica foi dada quanto ao manuseio dos brinquedos. O conjunto dos dados reuniu 36 vídeos.

Para a análise microgenética dos dados assistiu-se aos vídeos repetidas vezes com o propósito de observar minuciosamente o processo de comunicação registrado. Aliada com essa conduta assumiu-se também orientações descritas sobre o ciclo metodológico onde se considera os dados na pesquisa em psicologia como "representações seletivas, baseadas no binômio teoria $\mathrm{e}$ método, de determinados aspectos destacados dos fenômenos, que alimentam prospectivamente a construção posterior, de natureza teórica" (Valsiner, p. 302, itálico adicionado). Concretamente, a análise dos dados foram capturas seletivas de configurações na interação mãe-bebê registradas nos vídeos analisados, considerando-se para essa seleção, a composição entre a configuração da interação em questão, as explicações descritas na literatura sobre a comunicação no começo da vida e argumentos próprios do pesquisador que me- 
diava essa relação, entre teoria, fenômeno e método. Assim, as configurações selecionadas foram organizadas hierarquicamente no tempo cronológico dos registros que correspondiam também ao tempo de desenvolvimento do bebê. Essa organização hierárquica possibilitou a recuperação da trajetória histórica das configurações selecionadas que fundamentaram interpretações sobre o desenvolvimento da produção de sentidos no começo da vida.

\section{RESULTADOS E DISCUSSÕES}

Na medida em que se assistiu aos vídeos um acontecimento chamou atenção: a organização da comunicação mediada por brinquedos; foi possível observar diferentes momentos na reorganização de aspectos negociados na comunicação mediada por brinquedo, como por exemplo, mudanças nos modos de disposição, apresentação e manipulação dos brinquedos.

Alinhando-se as observações sobre a organização da comunicação mediada por brinquedos às questões conceptuais abordadas na introdução deste texto foi possível interpretar a produção de sentidos configurada na interação entre a mãe e o bebê considerando o movimento direcionado das experiências com o brinquedo, do passado para o futuro (Bakhtin, 1981/2010; 1979/2011). Neste direcionamento da produção e compartilhamento de informação, resgatou-se um movimento de experiências anteriores no curso de suas reorganizações, num nível mais elaborado em momentos posteriores, pois não se conseguiria falar do futuro sem se considerar momentos anteriores da relação construída.

A produção de sentidos, nesse contexto, foi concebida como o ato responsivo configurado no presente. Nesse ato responsivo os integrantes da díade sinalizaram o compartilhamento de informação o que possibili- tava interligação progressiva das experiências, evidenciando a direção do desenvolvimento. Essa foi a interpretação discutida aqui com o apoio de episódios selecionados. Nos recortes com os episódios selecionados para a apresentação e discussão dos resultados, o bebê tinha seis, nove, dez, vinte, vinte e cinco e vinte e sete semanas de vida, respectivamente.

A Figura 1, por exemplo, é uma sequência de situações ( $\mathrm{a}, \mathrm{b}$ e c) por onde se demonstrou como o brinquedo foi introduzido e constituído como mediador da comunicação entre a mãe o e bebê. A sequência de alternação de turnos nessa introdução (Figura 1a) foi caracterizada essencialmente por turnos de ação e sem a fala da mãe. A interação foi sustentada pela manutenção do olhar do bebê para a face da mãe e com o chocalho, enquanto a mãe o manuseava, produzindo uma sonoridade. Nessa situação a mãe explorou a atenção visual e auditiva do bebê que, nesse momento, estava com seis semanas de vida. Esta exploração foi incentivada pelas respostas do bebê ao sustentar a atenção conjunta para o objeto manuseado pela mãe. $\mathrm{Na}$ imagem seguinte (Figura 1b; bebê com nove semanas) observou-se outra configuração, ainda introdutória, relacionada à situação anterior. A principal diferença nessa segunda imagem foi a exploração da percepção tátil do bebê que foi conduzida pela mãe ao deslizar o brinquedo sobre a pele dele.

Assumiu-se que os movimentos na interação envolvendo o brinquedo nas duas primeiras imagens da Figura 1 (a e b) tratam-se, claramente, da introdução de uma história de trocas comunicativas. Essas primeiras imagens expressam o familiarizar-se do bebê com este objeto e com os modos como a mãe o utiliza na sua relação ele. Nas imagens, pode-se observar que a mãe apresentou o objeto/chocalho ao bebê e usou de suas propriedades para conquistar interesse dele.

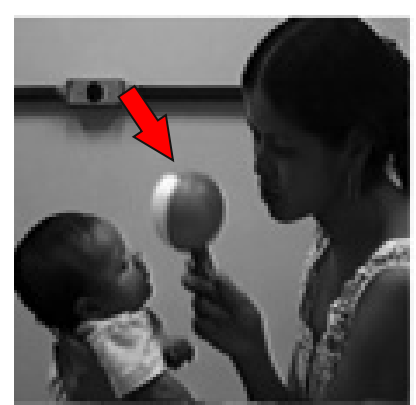

(a)

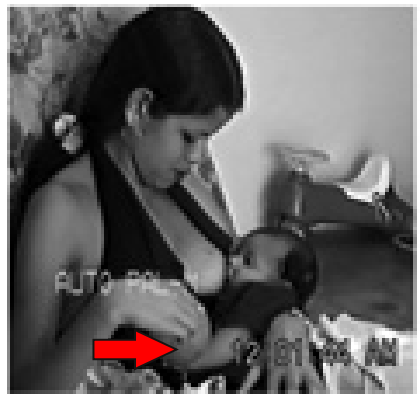

(b)

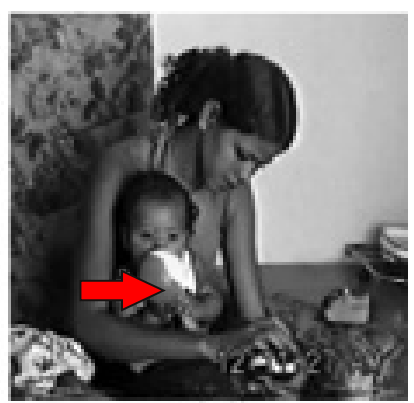

(c)

Figura 1. Introdução do brinquedo na comunicação. 
Quando o brinquedo já estava introduzido na comunicação da díade, através do olhar, do som e da sensação que causava na pele do bebê, a mãe providenciou a inclusão de novos elementos na função mediadora desse brinquedo; ela passou a incentivar ao bebê para que ele mesmo o segurasse. Assim, iniciaram-se sentidos onde não mais era, apenas, a mãe quem manuseava o chocalho; agora se antecipava a possibilidade de que o bebê também o manuseasse. Na direção dessa possibilidade antecipada, de que o bebê segurasse e agitasse o chocalho sozinho, a mãe passou a ajuda-lo a segurar o chocalho e este o levava constantemente à boca.

$\mathrm{Na}$ análise do modo como essa antecipação funcionava, observou-se que, enquanto estava no colo da mãe (Figura 1c), o bebê deixou o chocalho cair por cinco vezes. A mãe, então, apanhava-o e o colocava de volta em sua mão, aproveitando para the mostrar o movimento que se precisava fazer com o brinquedo, o de balançá-lo, que se contrapunha ao de pô-lo na boca. Por três vezes a mãe colocou sua mão abaixo das mãos do bebê, enquanto este segurava o brinquedo, para fazer junto com ele esse movimento. Essas trocas interativas foram transições sucessivas na construção e atualização de um passado e de uma trajetória que levou a concretização da possibilidade antecipada (de que o bebê segurasse e movimentasse o chocalho sozinho). Esse processo foi ilustrado aqui com as imagens nas Figuras 1(c) e 4 (a), quando o bebê estava com dez e vinte e sete semanas de vida, respectivamente.

Concebeu-se, então, que nas Figuras 1(c) e 4 (a) configuraram-se um ato responsivo, na medida em que o bebê segurou e balançou o chocalho sozinho, como lhe fora demonstrado pela mãe, em situações anteriores.
Ao segurar o objeto, o bebê respondeu aos investimentos da mãe; mas até chegar aí, ele e a mãe experimentaram variadas situações dirigidas por uma antecipação de possibilidades, vislumbradas nas ações da mãe, que culminou na caracterização desse ato responsivo. Foi, então, esse ato responsivo, sem o uso de palavras, o sentido á comunicação.

No conjunto dos registros videografados analisados nesta pesquisa, a antecipação de futuras possibilidades das experiências passadas do bebê, para a janela do tempo presente, foi frequentemente observada, sustentando a produção de sentidos na comunicação mediada pelo brinquedo. A intensidade e rapidez com que se expressam as mudanças no desenvolvimento humano no começo da vida talvez justifiquem os investimentos da mãe com as frequentes antecipações.

Com o apoio da Figura 2 ilustram-se como essas antecipações estiveram configuradas em progressivas reorganizações. Nesta imagem, o bebê estava na vigésima quinta semana de vida. A mãe estava agachada no tapete com algumas almofadas enquanto manuseava brinquedos dispostos em frente ao bebê. Quatro brinquedos estavam dispostos em frente do bebê. Com três deles (um telefone de cor rosa, um boneco do Mickey e outro chocalho) a criança nunca havia brincado. $\mathrm{O}$ quarto brinquedo era o chocalho introduzido no início dessa análise que foi mencionada na figura 1.

A mãe, então, mostrou-lhe o som do telefone (o segundo brinquedo da direita para esquerda, na linha dos quatro que foram dispostos em frente do bebê); em seguida, mostrou-lhe também o som do boneco do Mickey (colocado á esquerda do telefone) e do outro chocalho (que se encontrava à direita do telefone). Em

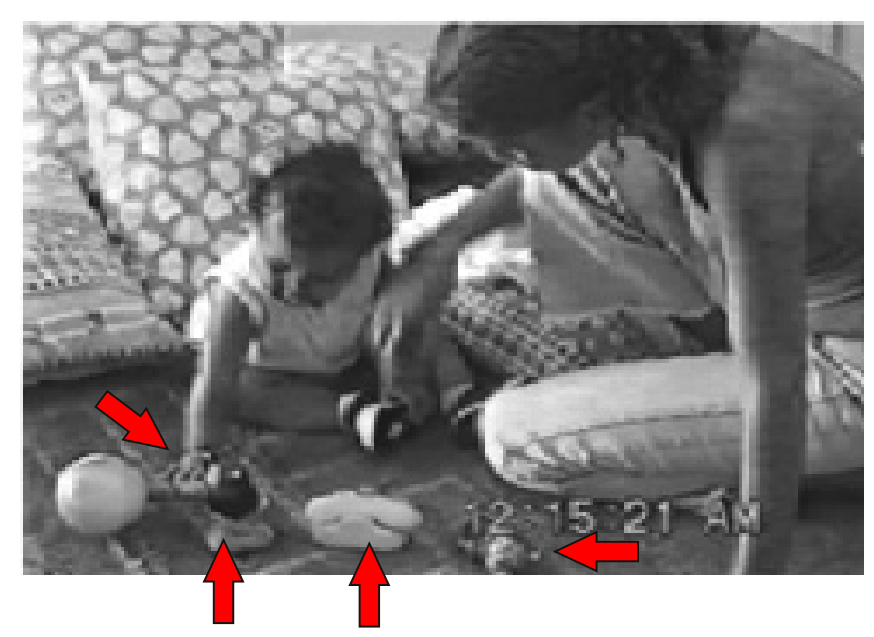

Figura 2. Introdução do conflito da escolha. 
determinado momento, o bebê levou a mão em direção ao chocalho que já conhecia e que também estava entre os outros brinquedos (Figura 2). No mesmo instante, a mãe mostrou-lhe o som de outro chocalho, com o qual ele ainda não havia brincado. Mas o bebê persistiu e pegou o chocalho que já conhecia.

Sugere-se que o compartilhamento de atenção no cenário constituído pelos brinquedos expresso na Figura 2 não teria lugar sem a consolidação do interesse do bebê pelo brinquedo construído como mediador da comunicação. Destaca-se nessa configuração dos dados, sobretudo, a oportunidade para ilustrar a função mediadora do brinquedo na interação distinguindo-se de uma função meramente instrumental (Vigotski, 1984/2010).

Na sua função mediadora o brinquedo atuou fazendo emergir um posicionamento inesperado do bebê. Isto é, distinguindo-se de um uso meramente instrumental, através da mediação do brinquedo relevaram-se possibilidades relacionadas com a semiogênese constitutiva dos processos psicológicos humanos. Fundamentalmente, essa semiogênese reflete a relação entre a experiência humana com a cultura e os processos criativos denunciados no funcionamento da linguagem (Vigotski, 1984/2010); ou a relação entre a cultura e os processos axiológicos, com suas vozes anunciadas nos usos de linguagem (Bakhtin, 1979/2011).

No recorte dos registros videografados analisados nesta pesquisa, ilustrado na figura 2 , esses processos criativos ou axiológicos foram ilustrados através da direção tomada pelo bebê diante dos diferentes brinquedos ativados pela mãe naquele momento. Criativo por que ele até então não tinha sido levado a uma situação de escolha, que era, portanto, uma experiência de novidade; axiológico por que para essa escolha ele precisou dotar de valor o objeto a ser escolhido. Além disso, nessa escolha, o ato criativo e axiológico refletiu como as experiências passadas foram renovadas considerando exigências circunstanciais do presente.

A experiência de tensão e conflito foi uma interpretação que se sugeriu, como consequência da atitude da mãe ao situar o bebê diante de diferentes brinquedos, enquanto os manuseava e revelava suas funções, tentando sobrepor a escolha do filho às outras possibilidades de escolha. Uma reorganização dos processos psicológicos do bebê se fez necessária para lidar com uma situação em que a sua mãe contradisse experiências anteriores, quando ela o incentivava e o ajudava a segurar aquele brinquedo específico; trata-se de uma experiência nova para o bebê, visto que agora a mãe dificultava o seu acesso ao brinquedo conhecido, na medida em que intensificava demonstrações dos sons emitidos por outros brinquedos.

Observou-se que o movimento do bebê ao pegar o brinquedo conhecido pressupôs uma experiência dupla na consciência, descrita na concepção dialógica da existência por Bakhtin (1979/2011), ao se referir à simultaneidade entre passado e futuro, ativada na janela do presente; pois, de acordo com Bakhtin, as pessoas percebem e interpretam suas lembranças no contexto de um passado inacabado. No exemplo que se discute aqui, a escolha do bebê expressou uma atualização (presente) do passado em coerência com as lembranças das suas experiências com o chocalho conhecido. Resume-se, então, que a atividade psicológica do bebê mediada pelo brinquedo, ao refletir experiências anteriores, transcendeu os limites da situação imediata, diferindo do que acontece no caso do uso instrumental de um objeto, que funciona nos limites da situação imediata. Dessa forma, a função mediadora do chocalho conhecido se revelou na medida em que as experiências do bebê com ele abriu possibilidades para a emergência de novas organizações do funcionamento psicológico. Essas reorganizações estão relacionadas com o potencial que o brinquedo no começo da vida assume para operar com elementos além da situação imediata.

Uma expansão desses argumentos pode ser favorecida com os acontecimentos ilustrados na Figura 3. Neste episódio o bebê, com vinte e cinco semanas de vida, segurava e balançava o chocalho quando este caiu de sua mão (Figura 3a); ele permaneceu olhando para o brinquedo caído e chorou; então a mãe o levantou (Figura $3 \mathrm{~b}$ ), dando-lhe suporte para que ele mesmo pudesse apanhar o chocalho (Figuras 3d).

Notou-se, a partir dessa sequência de ocorrências (e também com o auxílio da transcrição colocada no quadro 1), que o olhar do bebê em direção ao brinquedo acompanhado por seu choro reorganizou a situação comunicativa, na medida em que, naquele momento, foi ele quem esperou pela resposta da sua mãe, que o respondeu, ajudando-o para que ele mesmo pegasse o brinquedo.

Uma apreciação da sequência de imagens na Figura 3 e da sua transcrição (quadro 1), ascendeu a pergunta sobre o porquê da mãe colocar o bebê em pé quando o brinquedo caiu; por que ela agiu desta maneira, ao invés dela mesma apanhá-lo e coloca-lo na mão do bebê? $\mathrm{Na}$ microgênese dessas reorganizações das ações da 


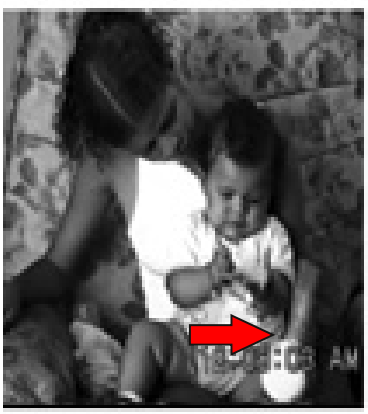

(a)

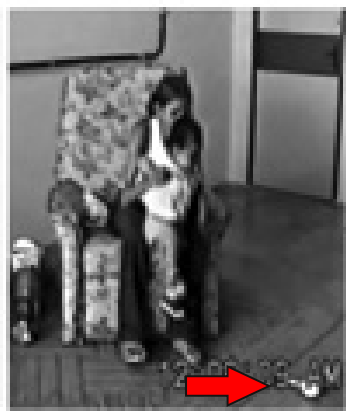

(b)

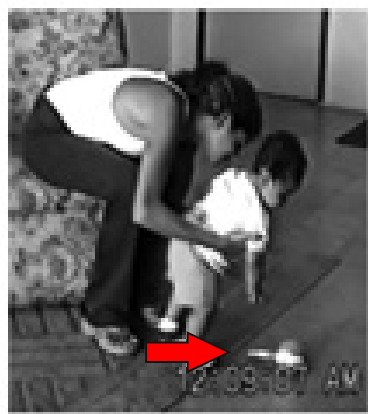

( c)

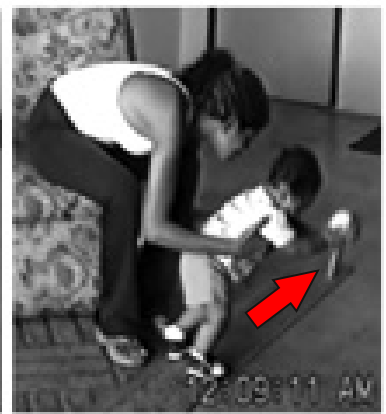

(d)

Figura 3. Antecipação de possibilidades 1.

mãe observou-se um movimento de alinhamento entre expectativas e respostas. Com o apoio também da transcrição da fala da mãe e dos aspectos não verbais com elas relacionados (Quadro 1) observou-se que, investindo nas suas expectativas, a mãe movimentou o bebê em direção ao chocalho (linha 4), incentivou-o 'vá pegar' (linha 6) enquanto agachou-o e disse 'abaixe' (linha 8). $\mathrm{O}$ bebê, por sua vez, respondeu às ações da mãe: olhou para o brinquedo e chorou (linha 5), tentando apanhar o brinquedo (linha 7).

Além disso, a ação da mãe ao posicionar o bebê em pé no chão fazendo-o dirigir-se ao brinquedo de seu interesse ilustrou mais uma situação de antecipação de possibilidades futuras de experiências passadas, que tem sido discutida nesta análise. É possível sugerir que, na perspectiva do bebê, ser colocado em pé, ao invés de receber o brinquedo na mão, revelou-se como mais um elemento novo na sua história da comunicação mediada pelo brinquedo. Assim se reforçou a função de media- ção do brinquedo na comunicação entre a díade, na medida em que a experiência de uma novidade pressupõe uma avaliação da história pregressa e, para isso, o bebê atuou não apenas com elementos fincados na situação imediata. O que emergiu, quando o bebê lidou com esse novo aspecto introduzido (não receber na mão o brinquedo caído), foram reorganizações na situação comunicativa que incluíram tanto aquelas experiências anteriores mediadas com o brinquedo como estas emergentes no presente, sob o efeito de suas avaliações da situação atual.

A sequência $(a, b$ e c) de imagens apresentadas na Figura 4 ilustra a intensificação da conduta de antecipação de possibilidades alvo de análise neste estudo. Neste episódio o bebê estava com vinte e sete semanas de vida. Sentado no chão ele brincava com o chocalho enquanto sua mãe estava sentada na poltrona (4a). Em seguida, a mãe deitou-o no chão (4b), retirou-lhe e afastou o brinquedo de sua mão (4c). Em resposta, o

Transcrição da Figura 3

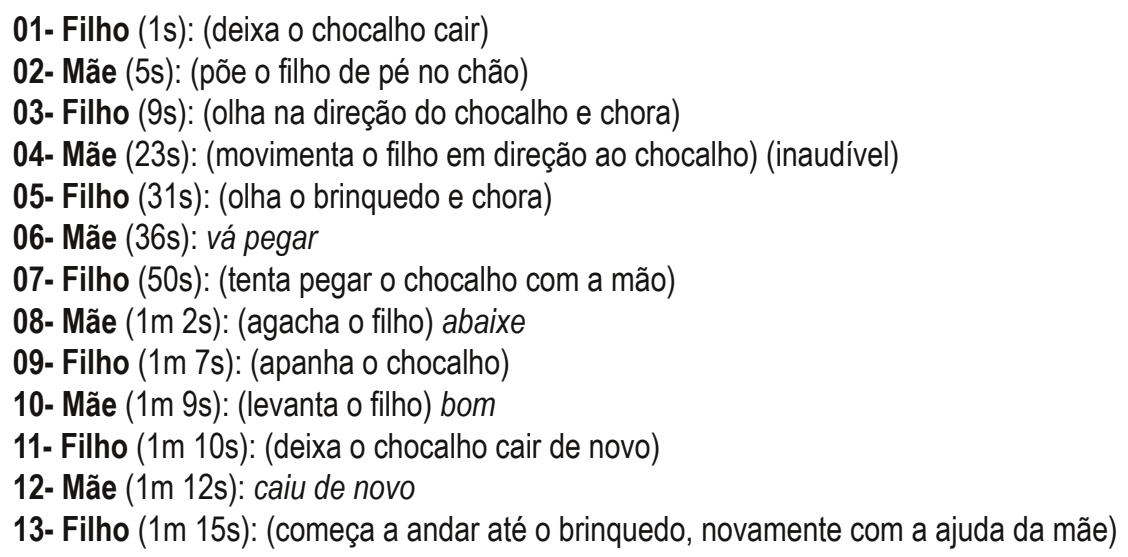




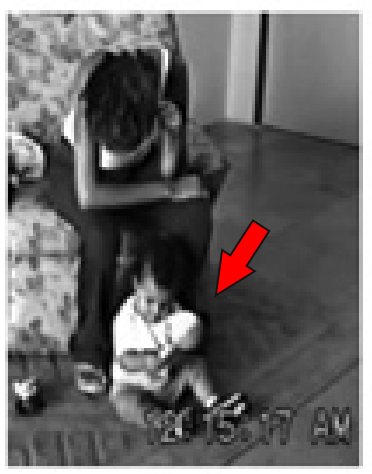

(a)

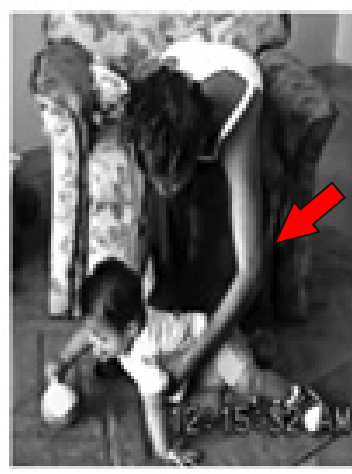

(b)

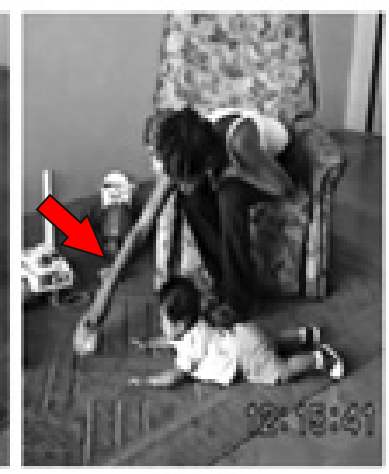

(c)

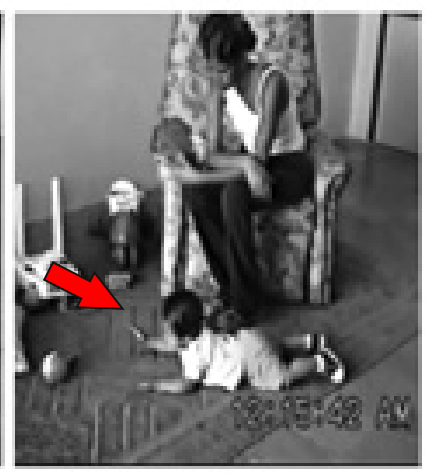

(d)

Figura 4. Antecipação de possibilidades 2.

bebê tentou alcançar o brinquedo (4d). Também nessa situação foi pertinente questionar, por que a mãe retirou o brinquedo da mão do bebê uma vez que, em experiências anteriores, muitas vezes ela apoiou suas mãos nas mãos do bebê para ajudá-lo a segurar aquele objeto?

Portanto, as sequências colocadas nas figuras 3 e 4 ilustram como a mãe explorou possibilidades futuras da comunicação mediada pelo chocalho a partir de antecipações, como a ação de colocar o bebê em pé e na retirada do brinquedo da mão do bebê respectivamente. $\mathrm{O}$ sentido dessas ações se realizou na medida em que o bebê respondeu, nos dois episódios, movimentando-se para alcançar o brinquedo.

$\mathrm{Na}$ interpretação que se elaborou com os dados do presente estudo, foi constitutiva da produção de sentidos configurações de atos responsivos na comunicação envolvendo o brinquedo. Esses atos responsivos denunciaram o vínculo, ativado no presente, entre experiências anteriores e posteriores; entre passado e futuro. Essa interpretação está em consonância também com as observações de Bakhtin ao declarar que "Chamo de sentido às respostas a perguntas. Aquilo que não responde nenhuma pergunta não tem sentido pra nós" (Bakhtin 1979/2011, pp.381). Além disso, o alinhamento entre ações e respostas faz a produção de sentidos ser sempre situada, circunstancial, instável e transicional. Acredita-se, que a variabilidade nesse alinhamento pressupõe a relação de reciprocidade entre interior e exterior necessária para se compreender a natureza social da consciência humana destacada por Bakhtin e Volochinov (1977/2009). Segundo esses filósofos essa reciprocidade é constitutiva das práticas com linguagem.

Os atos responsivos da mãe, ao posicionar o bebê para apanhar o brinquedo, ou do bebê, ao criar condições para as respostas da mãe, refletiram a co-regulação de ações inter e intrapsíquicas (Vigotski, 1934/2010). Isto porque a condição de resposta, enquanto ato manifesto na situação imediata pressupõe que os envolvidos na interação avaliaram a história das experiências com o alvo da atenção compartilhada, como já foi comentado anteriormente.

Todavia, a concretização de possibilidades antecipadas não é determinada a priori. Nessa observação implicam-se declarações feitas por Vigotski (1984/2010) acerca das formas como se criam realidades nas práticas com a linguagem. De acordo com Vigotski, esse processo abrange o percurso de experiências de quem está agindo, a história de seus costumes e valores, numa relação de reciprocidade entre o que já existia e o que emerge na ação imediata. Como foram ilustradas aqui, situações futuras sempre foram consideradas no alinhamento entre expectativas e respostas nas situações imediatas de comunicação mediada pelos brinquedos.

Considera-se, então, que foi o contexto de uma análise, onde já se dispunha de um conjunto de registros empíricos longitudinais, que suportou a captura do processo de antecipação de possibilidades futuras relacionadas com as experiências passadas e tornou visível a produção de sentidos enquanto direcionamento da interação. Isto é, ter-se de antemão o conjunto dos registros videografados foi fundamental para se interpretar a condição de futuro na configuração de determinadas ações praticadas no presente, tanto pela mãe quanto pelo bebê. Foi sobre possibilidades como essas que Lavelli et al (2002) referiram-se quando alegaram as vantagens dos dados longitudinais aliados à análise microgenética em estudos de um único caso; pois nessas condições metodológicas pode-se privilegiar uma descrição densa da trajetória individual do desenvolvimento de um determinado comportamento que, no presente 
caso, se tratou da produção de sentidos relacionada com comunicação no começo da vida mediada por brinquedo.

\section{CONSIDERAÇÕES FINAIS}

Nesta pesquisa investigou-se a produção de sentidos no começo da vida, onde se configuraram processos comunicativos predominantemente com pouca frequência de fala (na medida em que apenas a mãe se utilizou de palavras, considerando-se o aspecto fonológico). Uma abordagem psicológica da produção de sentidos teve o propósito de ampliar o foco de investigação que tem se voltado, frequentemente, para a análise do conteúdo de palavras.

A configuração da interação aqui considerada revelou a predominância de processos relacionados com a comunicação mediada por brinquedo. A análise dessa modalidade de comunicação possibilitou o enfoque em outros aspectos na produção de sentidos, destacando-se as reorganizações frequentes da situação interativa onde se revelou como experiências passadas se vincularam à antecipação de suas futuras possibilidades. Essa observação levou a intepretação de que a produção de sentidos é a forma como esse vínculo se realiza nos atos responsivos que caracterizam a situação comunicativa no aqui e agora.

Com o apoio da organização longitudinal dos registros da interação observou-se que a produção de sentidos emergiu como direção; como orientação no espaço microgenético de alinhamento entre expectativas e respostas. Concebeu-se, então, que mais relevante para sua explicação é, portanto, a historicidade, enquanto dinâmica orientada do passado para o futuro, das ações concretizadas nas demandas da situação interativa imediatamente presente.

Considerando-se as discussões tecidas na primeira parte deste texto, reforçam-se observações apontadas por Vigotski $(1934 / 2010$; 1984/2010) e por Bakhtin (1979/2011; 1981/2010), uma vez que, a partir delas, se pode compreender que as reorganizações focalizadas nesta análise constituíram-se como atos de criatividade. Isto porque se implicaram nessas reorganizações, disponibilidades dos envolvidos na interação para lidar com novidades; isto é, lidar com aspectos até então não experimentados na situação comunicativa.

As situações de novidades levam às reorganizações das experiências e pressupõem tensão e conflito entre ser coerente e reforçar aquelas já conhecidas (nos dados, por exemplo, quando o bebê insistiu em pegar o brinquedo já conhecido, ilustrado com a Figura 2) ou ser inovador e favorecer as bifurcações que levam as mudanças qualitativas no desenvolvimento (quando o bebê passou a ser diretor da interação e provocou as respostas da mãe, ilustrado quadro 1 , linhas 03 e 04 ). É possível dizer, portanto, que a produção de sentidos foi uma forma momentânea de resolver essas tensões. As reorganizações na situação comunicativa foram consequências dessas formas de resolução que pressupõem relações entre experiências de tempos diferentes (presente, passado e futuro) e relações entre processos de naturezas diferentes (biológicos, físicos, sociais e psicológicos).

Por fim, como contribuição teórica das análises aqui desenvolvidas apresentaram-se alguns parâmetros para se repensar o momento da convergência das linhas de desenvolvimento filogenético e ontogenético que Vigotski (1984/2010) se referiu, relacionando-o com a emergência da fala. Os argumentos aqui levantados sobre a função mediadora (e não apenas instrumental) do brinquedo no começo da vida, ao refletir processos semióticos que sustentaram a convergência de diferentes configurações tempo-espaço na situação de comunicação ineditamente presente, suportam a crença de que os processos especificamente humanos de mediação da cultura, para a constituição e funcionamento psicológico, tem atuação muito antes do momento de aquisição de fala. Os atos responsivos, concretizando situações antecipadas, foram indicativos de que o compartilhamento de significados e sentidos esteve presente já nas primeiras semanas do desenvolvimento humano.

\section{REFERÊNCIAS}

Bakhtin, M. (1981). The Dialogical Imagination: Four essays. (C. Emerson \& M.) Holquist, Trans.). Austin: University of Texas Press. (Texto original publicado em 2010)

Bakhtin, M. (1993). Toward a Philosophy of the Act. (V. Liapunov, Trans.). M. Holquist \& V. Liapunov (Eds.). Austin: University of Texas Press. (Texto original publicado em 1924)

Bakhtin, M. (2010). Problemas da poética de Dostoievski. Rio de Janeiro: Forense Universitária. (Texo original publicado em 1981)

Bakhtin, M. (2011). Estética da criação verbal. São Paulo: Editora WMF. (Original publicado em 1979)

Bakhtin, M., \& Voloschinov (2009). Marxismo e filosofia da linguagem. São Paulo: Editora Hucitec. (Texto original publicado em 1977)

Bertau, M. C., Gonçalves, M. M., \& Raggatt, P. T. (2013). Dialogic formations: Investigations into the origins and development of the dialogical self. Charlotte, NC: Information Age Publishing. 
Cavalcante, M. C. B. (2009). Rotinas interativas mãe-bebê: constituindo gêneros do discurso. Investigações, 2,153170. doi.org/10.5380/rinc.v1i2.44819.

Fogel, A. (2011). Theoretical and applied dynamic systems research in developmental science. Child Development Perspectives, 5, 267-272. doi: 10.1111/cdep.12185.

Holquist, M. (1994). Dialogism: Bakhtin and his world. London: Routledge.

Lavelli, M., Pantoja, A., Hsu, H., Messinger, D. \& Fogel, A (2002). Using Microgenetic Designs to Study Change Processes. In Teti, D. G. (Ed.), Handbook of Research Methods in Developmental Psychology (p.40-65). New York: Blackwell.

Motta, F. E., Rafalski, J. C., Rangel, I. C., \& Souza, M. L. (2013). Narrative and dialogical reflexivity: an approach between writing and inner speech. Psicol. Reflex. Crit. [online]. 26, 609-616. doi.org/10.1590/S010279721997000100002.

Silva, N. M. V., \& Vasconcelos, A. N. (2013). O self dialógico no desenho infantil. Psicol. Reflex. Crit., 26, 346-356. doi.org/10.1590/S0102-79721997000100002.

Sinha, C. (2013). (Dis-)contituity, (inter-)corporeality in dialogical development. Comentary on Gratier \& Bertau and Lyra. In, Dialogic formations: Investigations into the origins and development of the dialogical self (pp. 145-143). Charlotte, NC: Information Age Publishing.

Oliveira, M. (2006). Reviravolta lingüistico-pragmática na filosofia contemporânea. $3^{\mathrm{a}}$ edição. São Paulo: Edições Loyola.
Scorsi, L., \& Lyra, M. C. D. P. O. (2013). Manhês e o desenvolvimento da comunicação adulto-bebê: uma revisão da literatura com uma proposta de análise microgenética das trocas mãe-bebê. Interação em Psicologia, 16, 293-305. doi.org/10.5380/psi.v16i2.9138

Valsiner, J. (2012). Fundamentos da psicologia cultural: Mundos da mente, mundos da vida. São Paulo: Artmed.

Vieira, A. G., \& Henriques, M. R. A. (2014). Construção narrativa da identidade. Psicol. Reflex. Crit. [online], 27, 163-170.

Vigotski, L. S. (2010). A construção do Pensamento e da Linguagem. São Paulo: Martins Fontes. (Texto original publicado em 1934)

Vigotski, L.S. (2010). A Formação Social da Mente. São Paulo: Martins Fontes. (Texto original publicado em 1984)

Wittgenstein, Ludwig (1999). Philosophical Investigations. (G. E. M. Anscombe, Trans.). Oxford: Basil Blackwell. (Texto original publicado em 1968)

Recebido em: 07/07/2016 Primeira decisão editorial em: 20/09/2016 Aceito em: 27/09/2016 